Indonesian Journal of Pharmaceutical Science and Technology Journal Homepage : http://jurnal.unpad.ac.id/ijpst/

\title{
Isolation and Physicochemical Characterization of Microcristalline Cellulose from Ramie (Boehmeria nivea L. Gaud) Based on Pharmaceutical Grade Quality
}

\author{
Desy Nawangsari*, Anis Y. Chaerunisaa, Marline Abdassah, Sriwidodo Sriwidodo, \\ Taofik Rusdiana, Linda Apriyanti
}

Fakultas Farmasi, Universitas Padjadjaran, Jatinangor, Indonesia

Submitted 28 December 2017; Revised 01 February 2018; Accepted 14 February 2018; Pusblihed 27 June 2018

*Corresponding author: desynawang9@gmail.com

\begin{abstract}
Microcrystalline cellulose is a most used material for medicine, which is found in fibrous plants. Microcrystal celluloses are used as filler or binder in dosage formulas in tablets and capsules. This research aimed to produce microcrystalline cellulose from ramie based on pharmaceutical grade parameters. Research methods include hemp fiber preparation, $\alpha$-cellulose isolation, microcrystalline cellulose production, and microcrystalline cellulose characterization compared with Avicel ${ }^{\circledR} \mathrm{PH} 102$. The result showed that microcrystalline cellulose yield is $57.26 \%$. Based on its physicochemical characterization result, microcrystalline cellulose is able to meet pharmaceutical grade specification as a pharmaceutical excipient.
\end{abstract}

Keywords: Microcrystalline cellulose, pharmaceutical grade, physicochemical, ramie

\section{Isolasi dan Karakterisasi Fisikokimia Selulosa Mikrokristal dari Tanaman Rami (Boehmeria nivea L. Gaud) dengan Kualitas Pharmaceutical Grade}

\begin{abstract}
Abstrak
Selulosa mikrokristal merupakan bahan baku eksipien dalam pembuatan sediaan obat yang diperoleh dari tanaman berserat. Selulosa mikrokristal digunakan sebagai pengisi maupun pengikat pada formula tablet dan kapsul. Penelitian ini dilakukan untuk memperoleh selulosa mikrokristal dari tanaman rami yang dapat digunakan sebagai eksipien dengan kualitas pharmaceutical grade. Metode penelitian ini meliputi preparasi serat rami, isolasi $\alpha$-selulosa, pembuatan selulosa mikrokristal dan karakterisasi fisikokimia selulosa mikrokristal yang dibandingkan dengan Avicel ${ }^{\circledR}$ PH 102. Hasil penelitian menunjukan rendemen selulosa mikrokristal yaitu 57,26\%. Hasil karakterisasi fisikokimia memiliki karakteristik sesuai spesifikasi pharmaceutical grade sebagai eksipien sediaan farmasi.
\end{abstract}

Kata Kunci: Fisikokimia, pharmaceutical grade, rami, selulosa mikrokristal 


\section{Pendahuluan}

Selulosa mikrokristal merupakan bahan tambahan atau eksipien yang umum digunakan dalam farmasi. Terutama digunakan sebagai pengisi, pengikat serta dapat digunakan sebagai lubrikan dan disintegran pada formula tablet dan kapsul ${ }^{1}$. Selulosa mikrokristal yang telah beredar dipasar dengan nama dagang Avicel ${ }^{\circledR}$ PH, Emcocel ${ }^{\circledR}$ dan MCC Sanaq ${ }^{\circledR 2}$.

Selulosamikrokristal(MCC)merupakan hasil hidrolisis pengolahan $\alpha$-selulosa dengan larutan asam encer. Selulosa ini banyak terdapat di dalam pulp kayu atau tanaman berserat dengan asam mineral ${ }^{3}$.

Berdasarkan penelitian yang dilakukan oleh Jolandraw (2013), tanaman rami (Boehmeria nivea L. Gaud) digunakan sebagai salah satu solusi bahan baku pembuatan selulosa mikrokristal. Randemen selulosa mikrokristal yang dihasilkan sebesar 40,36\% . Menurut Karim (2014) metode pemanasan alkali dengan natrium hidroksida $25 \%$ menghasilkan kandungan $\alpha$ selulosa 97,29\% dan rendemen selulosa mikrokristal yaitu $64,11 \%{ }^{5}$. Metode pengeringan menggunakan spray dryer menghasilkan rendemen selulosa mikrokristal $56,80 \%{ }^{6}$. Dari uraian tersebut, penelitian mengenai isolasi dan karakterasasi selulosa mikrokristal dari tanaman rami yang memenuhi pharmaceutical grade perlu dilakukan.

\section{Metode}

2.1. Alat

Alat-alat yang digunakan dalam penelitian ini adalah oven, $\mathrm{pH}$ meter (Agilent Technologies 3200P), timbangan digital (Mettler Toledo), kaca arloji, pipa kapiler, mesh 60, melting point apparatus (Melttemp ${ }^{\circledR}$ Laboratory Device), krus tanur listrik, desikator, soxhlet, reflektrometer, gelas beaker, plate count agar (PCA), inkubator, media Potatoes Dextrosae Agar (PDA), tapped density tester (Erweka SVM 221), gelas ukur, cawan, piknometer, powder flow tester (Erweka GT), spray dryer.

\subsection{Bahan}

Bahan-bahan yang digunakan dalam penelitian ini adalah adalah serat kulit batang tanaman rami, Avicel ${ }^{\circledR}$ PH 102, akuades, asam asetat (Bratachem), natrium hidroksida (Bratachem), asam klorida (Bratachem), natrium hipoklorit (Bratachem),asam sulfat $\left(\mathrm{H}_{2} \mathrm{SO}_{4}\right)$ pekat (Merck), iodin (Merck), zink klorida (Merck), kalium iodida (Merck), kalium bromida (Merck), eter (J.T.Baker), alkohol 95\% (J.T.Baker), kalium permanganat (Merck), natrium tiosulfat (Merck), amilum (Merck), Plate Count Agar (PCA).

\subsection{Prosedur Rinci}

Serat batang rami kasar dengan kualitas tinggi (grade A) diperoleh dari Desa Simbang, Kabupaten Wonosobo. Kemudian dilakukan proses grinding sehingga didapatkan serat rami halus. Selanjutnya dilakukan proses isolasi $\alpha$-selulosa dengan metode pemanasan alkali. Serat halus rami dididihkan dengan larutan asam asetat $0,1 \mathrm{~N}$ perbandingan sampel terhadap pelarut 1:20, tahapan ini disebut prahidrolisis. Prahidrolisis dilakukan selama 1 jam dengan suhu $105^{\circ} \mathrm{C}$ kemudian sampel disaring dan dibilas berulang sampai $\mathrm{pH}$ netral. Kemudian dilanjutkan dengan pemanasan alkali menggunakan larutan natrium hidroksida $(\mathrm{NaOH}) \quad 25 \% \quad b / v$, dipanaskan pada suhu $105^{\circ} \mathrm{C}$ selama $1 \mathrm{jam}^{5}$. Pada tahap ini, akan terbentuk pulp berwarna coklat. Larutan yang berwarna coklat pekat merupakan indikasi dari terlarutnya senyawa-senyawa yang memiliki gugus kromofor yaitu gugus yang memiliki ikatan rangkap terkonjugasi yang menyebabkan suatu senyawa memiliki warna ${ }^{7}$. Warna dari terbentuk dapat dihilangkan melalui proses pemutihan. Pemutihan pulp dilakukan dengan cara perendaman $\alpha$-selulosa ke dalam larutan natrium hipoklorit selama 15-20 menit dengan perbandingan sampel dan pelarut 1:8. Kemudian larutan disaring dan residu dibilas dengan berulang sampai $\mathrm{pH}$ netral. Kemudian pulp dikeringkan dengan oven pada suhu $50^{\circ} \mathrm{C}$ selama 12-24 jam untuk selanjutnya dilakukan hidrolisis menjadi MCC.

Hidrosilis dilakukan dengan $\mathrm{HCl}$ 2,5 $\mathrm{N}$. dengan perbandingan sampel dan pelarut (1:20) pada suhu $105^{\circ} \mathrm{C}$ selama $15-20$ menit. Selama proses hidrolisis, terjadi pemisahan secara parsial pada penyusun mikrofibril 
Tabel 1. Karakteristik fisikokimia selulosa mikrokristal (MCC)

\begin{tabular}{lcc}
\hline \multicolumn{1}{c}{ Parameter } & MCC & Avice $^{\circledR}$ PH 102 \\
\hline Laju alir $(\mathrm{g} / \mathrm{s})$ & $1.74 \pm 0.03$ & $2.45 \pm 0.06$ \\
Kerapatan nyata $(\mathrm{g} / \mathrm{mL})$ & $0,346 \pm 0,003$ & $0,350 \pm 0,003$ \\
Kerapatan mampat $(\mathrm{g} / \mathrm{mL})$ & $0,472 \pm 0,009$ & $0,463 \pm 0,001$ \\
Kompresibilitas $(\%)$ & $26,72 \pm 1,91$ & $24,3 \pm 0,61$ \\
Faktor Hausner & $1,37 \pm 0,04$ & $1,33 \pm 0,01$ \\
Sudut diam $\left({ }^{\circ}\right)$ & $33.78 \pm 0.40$ & $32.04 \pm 1.10$ \\
\hline
\end{tabular}

selulosa dimana bentuk amorf akan putus dan meninggalkan bentuk kristalin yaitu daerah molekul selulosa yang tersusun teratur. Selanjutnya residu MCC dibilas sampai $\mathrm{pH}$ netral dan selanjutnya dikeringkan dengan spray dry sesuai yang dicantumkan oleh literatur ${ }^{1}$.

Karakteristik fisikokimia MCC dibandingkan dengan Avicel $^{\circledR}$ PH 102 meliputi: kerapatan nyata, kerapatan mampat, kompresibilitas, faktor hausner dan sudut diam. Kemudian dilakukan evaluasi selulosa mikrokristal dengan standar pharmaceutical grade.

\section{Hasil}

3.1. Sifat fisikokimia MCC

Hasil analisis karakteristik fisikokimia MCC dibandingkan dengan Avicel ${ }^{\circledR}$ PH 102 dapat dilihat pada Tabel 1. Pemeriksaan dengan analisis Fourier Transform Infrared (FTIR) dilakukan untuk mengidentifikasi gugus fungsi dari selulosa mikrokristal, spektrum dapat pada Gambar 1.

\subsection{Kualitas MCC dengan pharmaceutical grade}

Eksipien yang digunakan dalam sediaan farmasi harus memenuhi spesifikasi yang telah ditetapkan. Hasil evaluasi MCC

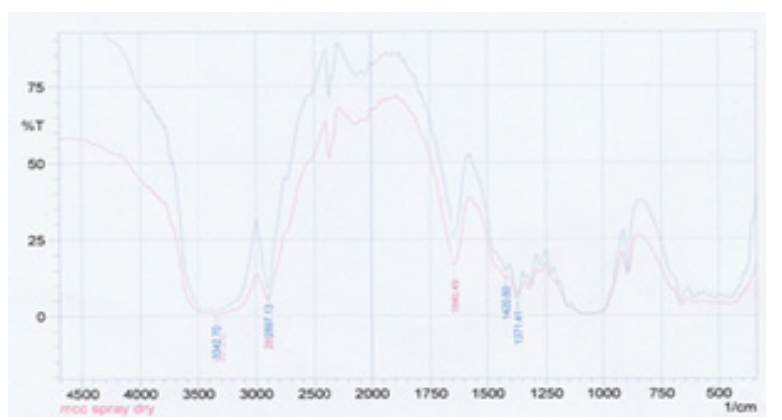

Gambar 1. Analisis MCC dengan FTIR berdasarkan syarat pharmaceutical grade. Hasil karakterisasi kualitas MCC ditunjukkan oleh Tabel 2.

\section{Pembahasan}

4.1. Sifat fisikokimia MCC

Selulosa mikrokristal yang dihasilkan dari tahapan isolasi memiliki rendemen $57,26 \%$. Laju alir merupakan suatu parameter penting pada pemilihan bahan pengisi untuk tablet cetak langsung. MCC memiliki laju alir $1,74 \mathrm{~g} / \mathrm{s}$, jika dibandingkan dengan Avicel $^{\circledR}$ PH 102 yang memiliki laju alir 2,45g/s maka selulosa mikrokristal memiliki lajur alir yang lebih kecil, namun berdasarkan Handbook of Pharmaceutical Excipients (2009) diketahui bahwa laju alir Emcocel ${ }^{\circledR} 90 \mathrm{M}$ yaitu 1,41 g/s. Hal ini menunjukan MCC maupun Avicel ${ }^{\circledR}$ PH 102 memenuhi standar yang terdapat pada literatur.

Perbandingan kerapatan nyata dan kerapatan mampat MCC dan Avicel ${ }^{\circledR}$ PH 102 secara berurut adalah 0,346 g/ $\mathrm{mL}$ dan $0,35 \mathrm{~g} / \mathrm{mL}$ serta $0,472 \mathrm{~g} / \mathrm{mL}$ dan $0,463 \mathrm{~g} / \mathrm{mL}$. Kemampuan mengalir MCC dalam alat pengempaan tablet ditentukan berdasarkan kompresibilitas, faktor hausner dan sudut diam. Semakin besar pesentase kompresibilitas dari nilai 21\% maka sifat alir serbuk makin kecil karena jika serbuk sangat rapat (kompresibilitas tinggi) maka akan sulit mengalir sehingga laju alir semakin buruk ${ }^{8}$. Hasil yang didapat menunjukkan bahwa selulosa mikrokristas (MCC) dan Avicel ${ }^{\circledR}$ PH 102 memiliki laju alir rendah dengan nilai kompresibilitas $26,72 \%$ dan $24,30 \%$. Sedangkan jika dibandingkan dengan Emcocel ${ }^{\circledR}$ 90M, maka selulosa mikrokristal (MCC) dan Avicel ${ }^{\circledR}$ PH 102 memiliki nilai kompresibilitas yang lebih kecil. Secara 
Tabel 1. Karakterisasi kualitas MCC sesuai pharmaceutical grade

\begin{tabular}{|c|c|c|c|}
\hline $\begin{array}{c}\text { Karakterisasi } \\
\text { Pharmaceutical } \\
\text { Grade }\end{array}$ & MCC & Syarat & Kesimpulan \\
\hline Kadar air (\%) & 4,95 & $<5$ & Sesuai \\
\hline Identifikasi kualitatif & & & Sesuai \\
\hline perubahan warna & violet biru & violet biru & \\
\hline bentuk & hablur & hablur & \\
\hline warna & putih & putih & \\
\hline Organoleptis & & & Sesuai \\
\hline bau & tidak berbau & tidak berbau & \\
\hline rasa & tidak berasa & tidak berasa & \\
\hline Kelarutan & & & Sesuai \\
\hline air & tidak larut & tidak larut & \\
\hline alkohol 96\% & tidak larut & tidak larut & \\
\hline $\mathrm{HCl} 2 \mathrm{~N}$ & tidak larut & tidak larut & \\
\hline $\mathrm{NaOH} 1 \mathrm{~N}$ & tidak larut & tidak larut & \\
\hline Eter & tidak larut & tidak larut & \\
\hline Titik Leleh $\left({ }^{\circ} \mathrm{C}\right)$ & 262,6 & $260-270$ & Sesuai \\
\hline $\mathrm{pH}$ & 7,13 & $5-7,5$ & Sesuai \\
\hline Susut Pengeringan $(\%)$ & 4,86 & $\leq 7$ & Sesuai \\
\hline Sisa Pemijaran (\%) & 0,083 & $\leq 0,1$ & Sesuai \\
\hline Derajat Putih & putih & putih & Sesuai \\
\hline $\begin{array}{l}\text { Bilangan } \\
\text { Permanganat (\%) }\end{array}$ & 2,018 & $<6$ & Sesuai \\
\hline $\begin{array}{l}\text { Cemaran } \\
\text { Mikroba (cfu/g) }\end{array}$ & & & Sesuai \\
\hline Bakteri & 0 & $\leq 1000$ & \\
\hline Jamur & 0 & $\leq 100$ & \\
\hline Cemaran Logam Berat & & & Sesuai \\
\hline Merkuri (Hg) & $\leq 0,01 \mu \mathrm{g} / \mathrm{kg}$ & $\leq 1 \times 10-2$ & \\
\hline Kadmium $(\mathrm{Cd})$ & $\leq 0,001 \mathrm{mg} / \mathrm{kg}$ & $\leq 1 \times 10-2$ & \\
\hline Timbal $(\mathrm{Pb})$ & $\leq 0,001 \mathrm{mg} / \mathrm{kg}$ & $\leq 1 \times 10-2$ & \\
\hline Timah (Sn) & $\leq 0,001 \mathrm{mg} / \mathrm{kg}$ & $\leq 1 \times 10-2$ & \\
\hline
\end{tabular}

berurut nilai kompresibilitas $\mathrm{MCC}$, Avicel ${ }^{\circledR}$ PH 102 dan Emcocel ${ }^{\circledR} 90$ M adalah 26,72\%, $24,3 \%$ dan $29,9 \%$.

Nilai faktor hausner MCC dan Avicel ${ }^{\circledR}$ PH 102 yaitu 1,37 dan 1,33. Hasil nilai faktor hausner yang mendekati 1 maka sifat alir serbuk semakin baik untuk pencetakkan tablet. Nilai Hf yang jauh lebih besar daripada 1 maka sifat alirnya semakin buruk karena akan terjadi variasi terhadap massa tablet yang akan dicetak 9 .

Sudut diam juga menunjukkan kemampuan MCC mengalir. Kisaran sudut diam 25-30, 30-39, 40-45, dan $>45^{\circ}$ berurutan menunjukkan sangat mudah mengalir, mudah mengalir, mengalir, dan laju alir rendah ${ }^{8}$. MCC dan Avicel ${ }^{\circledR}$ PH 102 dikategorikan mampu mengalir dengan nilai sudut $33,78^{\circ}$ dan $32,04^{\circ}$. Jika dibandingkan dengan standar pada Handbook of Pharmaceutical Excipients (2009) diketahui Emcocel ${ }^{\circledR}$ 90M memiliki sudut diam 34,4 maka baik MCC dan Avicel ${ }^{\circledR}$ PH 102 memenuhi standar.

Hasil puncak serapan yang dimiliki 
Avicel $^{\circledR}$ PH 102 pembanding dan selulosa mikrokristal hasil isolasi yakni pada bilangan gelombang $3349,53 \mathrm{~cm}^{-1}$ dan $3310,87 \mathrm{~cm}^{-1}$ yaitu puncak serapan gugus $\mathrm{OH}$, pada bilangan gelombang 2900,105 $\mathrm{cm}^{-1} \mathrm{dan}$ $2898,10 \mathrm{~cm}^{-1}$ yaitu puncak serapan $\mathrm{C}-\mathrm{H}$ regang, pada bilangan gelombang 1437,03 $\mathrm{cm}^{-1}$, dan $1640,49 \mathrm{~cm}^{-1}$ yaitu puncak serapan $\mathrm{C}-\mathrm{H}$ bending, pada bilangan gelombang $1371,45 \mathrm{~cm}^{-1}$ dan $1374,30 \mathrm{~cm}^{-1}$ yaitu puncak serapan C-O. Prediksi gugus fungsi tersebut menunjukan bahwa produk hasil isolasi adalah benar selulosa mikrokristal dengan Avicel ${ }^{\circledR}$ PH 102 sebagai baku pembanding.

\subsection{Kualitas MCC sesuai dengan pharma-} ceutical grade

Kualitas serbuk selulosa mikrokristal diuji dari segi sifat fisika-kimia untuk mengidentifikasi secara kualitatif. Kualitas yang dihasilkan kemudian dibandingkan literatur yaitu USP Vol. 37. Hasil identifikasi kualitatif yang dilakukan didapat hasil perubahan warna dari pemberian iodinated zinc chloride terhadap sampel MCC yang semula putih menjadi warna violet-biru tua terdispersi, warna violet-biru tua yang sama ditunjukan pada pemberian iodinated zinc chloride.

Pengamatan organoleptis dari tampilan bentuk, warna, bau, dan rasa menunjukan karakteristik yang sama diantara sampel dan literatur yaitu serbuk hablur, berwarna putih, tidak berbau, dan tidak berasa. Kriteria ini sesuai dengan monografi selulosa mikrokristal.

Dari hasil uji kelarutan serbuk MCC didapat bahwa selulosa mikrokristal tidak larut dalam 4 pelarut yang diujikan yaitu air, alkohol 95\%, $\mathrm{HCl} 2 \mathrm{~N}$, natrium hidroksida $1 \mathrm{~N}$ dan eter. $\mathrm{MCC}$ sulit untuk terlarut dalam pelarut karena adanya ikatan hidrogen yang kuat antar gugus hidroksil pada rantai ikatan yang berdekatan pada struktur kristalin penyusun selulosa mikrokristal. Dari hasil pemeriksaan kualitas serbuk menunjukkan bahwa senyawa hasil isolasi adalah benar selulosa mikrokristal.

Pengujian kadar air dilakukan dengai alat moisture balance. MCC ditimbang 10 gram dan dimasukan pada spaciment yang tersedia pada alat. Hasil menunjukan bahwa kadar air dari MCC yaitu sebesar 4,95\% yang artinya MCC mengandung air sebesar 4,95\%, kadar air tersebut masih dalam rentang persyaratan Handbook of Pharmaceutical Excipients yaitu kurang dari 5\%. Kandungan air di dalam MCC sebagian besar telah hilang pada proses pengeringan dengan spray dry.

Pengujian titik leleh dilakukan dengan melting poin apparatus. Sampel MCC dimasukkan kedalam pipa kapiler dan diatur suhu dengan kenaikan $5^{\circ} \mathrm{C}$ setiap menit.

Titik leleh MCC yaitu $262,6^{\circ} \mathrm{C}$, nilai ini sesuai dari literatur Handbook of Pharmaceutical Excipients (2009) dimana titik leleh selulosa mikrokristal berada direntang $260-270^{\circ} \mathrm{C}$.

Penetuan $\mathrm{pH}$ dilakukan dengan $\mathrm{pH}$ meter digital, dengan cara mendispersikan MCC $15 \%$ kedalam aquadest ${ }^{10}$. Hasil pengujian menunjukan pH MCC adalah 7,13. Hasil tersebut berada pada rentang $\mathrm{pH}$ yang tertera pada literatur yaitu $\mathrm{pH}$ 5,0-7,5.

Nilai susut pengeringan MCC yaitu $4,86 \%$. Nilai susut pengeringan masih memenuhi kriteria dari literatur yaitu tidak lebih atau sama dengan 7,0\%.

Parameter uji serbuk selanjutnya adalah analisis sisa pemijaran bertujuan untuk menunjukkan adanya abu yang tidak habis terbakar pada tanur listrik dengan suhu $700^{\circ} \mathrm{C}$. Hal ini dapat menunjukkan adanya unsur anorganik seperti mineral yang memiliki titik lebur yang lebih tinggi dari suhu pengabuan tersebut ${ }^{8}$. MCC memiliki kadar abu sebesar $0,083 \%$ yang berada di rentang persyaratan sisa pemijaran sesuai literatur Handbook of Pharmaceutical Excipients (2009) yaitu kurang dari sama dengan $0,1 \%$ b/b sampel uji.

Pengujian derajat putih pada MCC diperlukan untuk menentukan kualitas warna serbuk. Warna serbuk yang akan dijadikan eksipien sebaiknya berwarna putih agar tidak mengganggu penampilan sediaan yang dihasilkan, selain itu juga mengikuti standar Handbook of Pharmaceutical Excipients (2009) yang menyatakan bahwa selulosa mikrokristal harus berwarna putih. Oleh karena itu, diperlukan pengukuran derajat 
putih untuk mengukur tingkat warna putih dari sampel dengan metode SNI ISO 2470:2010. Metode ini menggunakan alat reflektometer untuk mengukur derajat putih pada pulp yang dibuat dalam bentuk lembaran. Serbuk dibuat dalam bentuk lembaran kemudian lembaran ini akan memantulkan cahaya yang diukur dan dinyatakan dalam persen.

Selulosa mikrokristal hasil isolasi menghasilkan derajat putih sebesar $84,64 \%$. Adanya sisa kandungan lignin yang terdapat pada selulosa hasil isolasi menyebabkan warna selulosa menjadi kurang putih karena lignin berikatan dengan selulosa sehingga nilai derajat putih yang didapat tidak optimal ${ }^{11}$.

Kualitas MCC dapat ditentukan dengan pengujian bilangan permanganat untuk mengetahui kadar lignin yang masih terkandung sebagai pengotor dalam sampel yang berpengaruh terhadap kemurniannya. Pengujian bilangan permanganat dilakukan terhadap pulp dengan kadar lignin dibawah $6 \%$. Hasil perhitungan bilangan permanganat MCC yaitu 2,018\%, hal tersebut menunjukkan bahwa selulosa mikrokristal yang dihasilkan masih memiliki kandungan lignin. Lignin yang terkandung dalam serat rami diurai melalui proses delignifikasi dan terlarut di dalam natrium hidroksida $25 \%$, sisa lignin dan karbohidrat yang tidak terurai sempurna dan masih tersisa di pulp $^{12}$.

Uji cemaran mikroba dilakukan dengan metode total plate count untuk melihat pertumbuhan mikroba melalui jumlah koloni bakteri dan jamur. Media yang digunakan adalah Plate Count Agar (PCA) untuk melihat total mikroba dalam suatu sampel. Cemaran bakteri harus tidak lebih besar dari 1000 $\mathrm{cfu} / \mathrm{g}$ terhadap bakteri aerob, Staphylococcus aureus, Pseudomonas aeruginosa, Escherichia coli, Salmonella sp. Sedangkan untuk uji cemaran jamur, digunakan media Potatoes Dextrosae Agar (PDA) karena nutrisinya cocok untuk pertumbuhan jamur ataupun ragi. Cemaran jamur harus tidak lebih besar dari $100 \mathrm{cfu} / \mathrm{g}$ terhadap Molds dan Yeasts. Pengujian selulosa mikrokristal hasil isolasi tidak terdapat pertumbuhan cemaran mikroba. Adanya proses pemanasan pada suhu tinggi dengan spray dry dapat memungkinkan kecilnya pertumbuhan bakteri dan jamur?

MCC umumnya digunakan sebagian besar untuk bahan baku obat, cemaran logam berat diuji untuk menentukan kandungan yang terdapat pada sampel. Logam yang diuji sesuai yang dipersyaratkan dalam SNI 01-2896-1998 seperti kadmium (Cd), merkuri (Hg), timah (Sn) dan timbal $(\mathrm{Pb})$. Pengujian kandungan logam berat menggunakan instrumen Absorption Atomic Spectrofotometry.

Hasil cemaran logam MCC yang diuji menggunakan instrumen AAS, semuanya dibawah batas persyaratan menurut USP 37-NF 32. Kadmium (Cd), merkuri $(\mathrm{Hg})$, timah ( $\mathrm{Sn})$ dan timbal $(\mathrm{Pb})$ merupakan logam berat yang tidak baik bagi tubuh manusia bila dikonsumsi, kadar timbal yang terkandung didalam MCC dapat berasal dari bahan bakunya yaitu tanaman rami yang dipengaruhi dari lingkungan tempat tanaman rami tumbuh, baik berasal dari kandungan tanah maupun polusi udara.

\section{Simpulan}

Selulosa mikrokrstal hasil isolasi menunjukan hasil karakterisasi fisikokimia terkait laju alir, kompresibilitas, faktor hausner dan sudut diam lebih kecil dari selulosa mikrokrstal komersial (Avicel ${ }^{\circledR}$ PH 102). Selulosa mikrokrital hasil isolasi tanaman rami memenuhi spesifikasi pharmaceutical grade.

\section{Daftar Pustaka}

1. Rowe RC, Sheskey PJ, dan Quinn ME. Handbook of Pharmaceutical Excipient, 6th Edition. USA: American Pharmacist Association; 2009.

2. Siregar, C.J.P. dan Wikarsa, S. Teknologi Farmasi Sediaan Tablet: Dasar-Dasar Praktis. Jakarta: EGC; 2010.

3. Department of Health and Human Services US. The United States Pharmacopoeia, Thirtieth RevisionThe National Formulary, Twenty-Fifth Edition. Rockville, Maryland: United States Pharmacopoeial Convention, Inc; 2008.

4. Jolandraw, T. Karakterisasi Selulosa 
Mikrokristal dari Tanaman Rami (Boehmeria nivea L. Gaud.) sebagai Eksipien Sediaan Farmasi (skripsi). Bandung: Universitas Padjadjaran; 2013.

5. Karim, R. Pengaruh Variasi konsentrasi Natrium Hidroksida terhadap pembuatan Selulosa mikrokristal dari tanaman rami (Boehmeria nivea, L. Gaud.) Sebagai Eksipien Sediaan Farmasi (skripsi). Bandung: Universitas Padjadjaran; 2014.

6. Apriyanti, Linda. Pengaruh Proses Pengeringan Terhadap Kualitas Selulosa Mikrokristal dari Rami (Boehmeria nivea L. Gaud.) sebagai eksipien farmasi dengan kualitas pharmaceutical grade (skripsi). Bandung : Universitas Padjadjaran; 2017.

7. Hamisan, A. F., Abd-Aziz dan Kamaruddin: Delignification of oil palm empty fruit bunch using chemical and microbial pretreatment methods, International Journal of Agricultural Research, 2009; 4 (8): 250-256.

8. Azubuike C.P. dan Okhamafe A.O. Physicochemical, spectroscopic, and thermal properties of microcrystalline cellulose derivied from corn crobs. Int Journal Recycling of Org Waste Agric. 2012; 1(9): 1 - 7 .

9. Ben, E.S. Teknologi Tablet. Padang. Andalas University Press; 2008.

10. Thoorens, Gregory., Fabrice Krier, Bruno Leclercq, Brian Carlin, Brigitte Evrard. Understanding the impact of microcrystalline cellulose physicochemical properties on tabletability. International Journal of Pharmaceutics. 2015; 490 (1-2), 47-54.

11. Sagitaria,A. S. Preparasi dan Karakterisasi Selulosa Mikrokristal dari Nata De Soya sebagai Eksipien Tablet dengan Metode Kempa Langsung (skripsi). Bandung: Universitas Padjadjaran; 2011.

12. Behin, J., Mikaniki, F., dan Fadaei, Z. Dissolving Pulp (alpha-cellulose) from Corn Stalk by Kraft Process, Iranian Journal of Chemical Engineering. 2008; 5 (3): 14-28. 